\title{
Skeletal muscle energy metabolism during exercise
}

\author{
Mark Hargreaves $\oplus^{1 凶}$ and Lawrence L. Spriet $\oplus^{2} \bowtie$
}

\begin{abstract}
The continual supply of ATP to the fundamental cellular processes that underpin skeletal muscle contraction during exercise is essential for sports performance in events lasting seconds to several hours. Because the muscle stores of ATP are small, metabolic pathways must be activated to maintain the required rates of ATP resynthesis. These pathways include phosphocreatine and muscle glycogen breakdown, thus enabling substrate-level phosphorylation ('anaerobic') and oxidative phosphorylation by using reducing equivalents from carbohydrate and fat metabolism ('aerobic'). The relative contribution of these metabolic pathways is primarily determined by the intensity and duration of exercise. For most events at the Olympics, carbohydrate is the primary fuel for anaerobic and aerobic metabolism. Here, we provide an overview of exercise metabolism and the key regulatory mechanisms ensuring that ATP resynthesis is closely matched to the ATP demand of exercise. We also summarize various interventions that target muscle metabolism for ergogenic benefit in athletic events.
\end{abstract}

n 2020, athletes from around the world were to gather in Tokyo for the quadrennial Olympic festival of sport, but the event has been delayed until 2021 because of the COVID-19 pandemic. When the Olympics takes place, we will witness extraordinary physical and mental efforts in track and field, water and air. Perhaps we may wonder how these feats are achieved. Such efforts are a culmination of years of dedicated training, and athletic performance is determined by a complex interaction of biological, mental and environmental factors. The availability of ATP is critical for skeletal muscle contractile activity, both in explosive-power or sprint events lasting for seconds or minutes and in endurance events lasting for hours.

ATP is required for the activity of key enzymes involved in membrane excitability $\left(\mathrm{Na}^{+} / \mathrm{K}^{+}\right.$ATPase $)$, sarcoplasmic reticulum calcium handling $\left(\mathrm{Ca}^{2+}\right.$ ATPase $)$ and myofilament cross-bridge cycling (myosin ATPase). Because the intramuscular stores of ATP are relatively small ( $\sim \mathrm{mmol}$ per $\mathrm{kg}$ wet muscle), they are unable to sustain contractile activity for extended periods. For example, during all-out, maximal exercise (such as sprinting) at a power output of $900 \mathrm{~W}\left(\sim 300 \%\right.$ maximal oxygen uptake $\left.\left(\mathrm{VO}_{2} \max \right)\right)$, the estimated rate of ATP utilization is $3.7 \mathrm{mmol} \mathrm{ATP} \mathrm{kg}^{-1} \mathrm{~s}^{-1}$, and exercise could last $<2 \mathrm{~s}$ if stored ATP were the sole energy source. During submaximal exercise at $\sim 200 \mathrm{~W}\left(\sim 75 \% \mathrm{VO}_{2} \max \right)$, the corresponding values are $0.4 \mathrm{mmol}$ ATP $\mathrm{kg}^{-1} \mathrm{~s}^{-1}$ and $\sim 15 \mathrm{~s}$, respectively.

Therefore, other metabolic pathways must be activated (Box 1), including substrate-level phosphorylation (or anaerobic) and oxidative phosphorylation (or aerobic). The latter is critically dependent on the respiratory and cardiovascular systems, to ensure adequate oxygen delivery to contracting skeletal muscle, and on reducing equivalents from the metabolism of primarily carbohydrate and fat ${ }^{1}$. The anaerobic energy pathways have a much higher power (rate of ATP production) but a smaller capacity (total ATP produced) than the aerobic pathways ${ }^{2}$. In terms of oxidative metabolism, carbohydrate oxidation has a higher power output but a lower capacity than fat oxidation; this is one factor contributing to the decrease in power output with carbohydrate depletion during prolonged strenuous exercise ${ }^{2}$. This Review provides a brief overview of exercise metabolism and a summary of the key regulatory mechanisms, and identifies potential strategies that target metabolism for ergogenic benefit during athletic events.

\section{Overview of exercise metabolism}

The relative contribution of the ATP-generating pathways (Box 1) to energy supply during exercise is determined primarily by exercise intensity and duration. Other factors influencing exercise metabolism include training status, preceding diet, sex, age and environmental conditions. Generally, Olympic-calibre athletes are well trained, follow a good diet, and tend to be younger and to be well adapted to the environmental conditions in which they train. Later in the Review, we will touch on some of these factors in the context of performance and will briefly cover sex differences in metabolism.

During very intense efforts lasting seconds (such as throws, jumps or 100- to 400-m sprints) or during intermittent game activities and field sports, most ATP is derived from the breakdown of phosphocreatine (PCr) and glycogen to lactate. Direct measurements of muscle $\mathrm{PCr}$ and glycogen before, during and after such exercise bouts show substantial decreases in the levels of these substrates $^{3,4}$ (Fig. 1). The decrease is generally greater in type II than type I muscle fibres ${ }^{5}$. The muscle ATP concentration is reasonably well maintained, although it may decrease by $\sim 20 \%$ during very intense exercise ${ }^{5}$. The large increases in ATP utilization and glycolysis, as well as the strong ion fluxes during such exercise, result in metabolic acidosis. After the exercise duration extends beyond approximately $1 \mathrm{~min}$ (for example, in an $800-\mathrm{m}$ track event), oxidative phosphorylation is the major ATP-generating pathway ${ }^{6}$, and intramuscular glycogen is the dominant fuel source. Although it is relatively less studied, resistance exercise, as seen during lifting events, is also associated with substantial metabolic perturbations in contracting skeletal muscle ${ }^{7,8}$.

During events lasting several minutes to hours, the oxidative metabolism of carbohydrate and fat provides almost all the ATP for contracting skeletal muscle. Even during marathon and triathlon events lasting $2-2.5 \mathrm{~h}$, there is a primary reliance on carbohydrate oxidation $^{9,10}$. The major intramuscular and extramuscular substrates

'Department of Physiology, University of Melbourne, Melbourne, Victoria, Australia. ${ }^{2}$ Department of Human Health and Nutritional Sciences, University of Guelph, Guelph, Ontario, Canada.凶e-mail:m.hargreaves@unimelb.edu.au; Ispriet@uoguelph.ca 


\section{Box 1 | Energy metabolism in skeletal muscle}

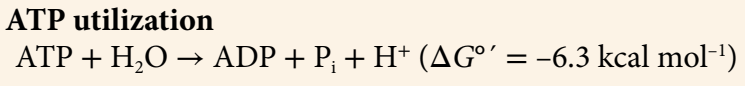

ATP resynthesis

Substrate-level phosphorylation

$\mathrm{PCr}+\mathrm{ADP}+\mathrm{H}^{+} \rightarrow \mathrm{ATP}+$ creatine

$2 \mathrm{ADP} \rightarrow \mathrm{ATP}+\mathrm{AMP}$

Glycogen $_{n}{ }^{a}+3$ ADP $+3 \mathrm{P}_{\mathrm{i}} \rightarrow$ glycogen $_{n-1}+2$ lactate +3 ATP

Oxidative phosphorylation

Glucose $+6 \mathrm{O}_{2}+36 \mathrm{ADP} \rightarrow 6 \mathrm{CO}_{2}+6 \mathrm{H}_{2} \mathrm{O}+36 \mathrm{ATP}^{\mathrm{b}, \mathrm{c}}$

Palmitate $+23 \mathrm{O}_{2}+130 \mathrm{ADP} \rightarrow 16 \mathrm{CO}_{2}+16 \mathrm{H}_{2} \mathrm{O}+130 \mathrm{ATP}^{\mathrm{b}, \mathrm{c}}$

${ }^{a}$ Muscle glycogen is the primary $\mathrm{CHO}$ source during intense exercise. Glycogen a glycogen polymer of $n$ glucose residues. ${ }^{\text {b}}$ The total ATP yield includes that from substrate-level phosphorylation in glycolysis and the TCA cycle. ${ }^{\text {CATP }}$ yields reported are based on the traditionally used value of 3 ATP per NADH, but if the more contemporary values of 2 or 3 ATP per NADH were used, the actual ATP yields would be lower; however, the relative contributions of glucose and palmitate to overall ATP generation remain the same.

are muscle glycogen, blood glucose (derived from liver glycogenolysis and gluconeogenesis, and from the gut when carbohydrate is ingested) and fatty acids derived from both muscle (intramuscular triglyceride (IMTG)) and adipose tissue triglyceride stores. These stores and the relative energy available from them are shown in Fig. 2. The primary determinants of the relative contribution of these substrates to oxidative metabolism are exercise intensity and duration $^{11,12}$ (Fig. 3).

Carbohydrate oxidation, particularly from muscle glycogen, dominates at higher exercise intensities, whereas fat oxidation is more important at lower intensities. Maximal rates of fat oxidation occur at $\sim 60-65 \% \mathrm{VO}_{2}$ max. Oxidation of muscle glycogen and fatty acids derived from IMTG is greatest during the early stages of exercise and declines as exercise duration is extended, coinciding with progressive increases in muscle glucose and fatty acid uptake and oxidation ${ }^{13-17}$. Accompanying the increase in muscle glucose uptake is an increase in liver glucose output ${ }^{15,18}$ from both liver glycogenolysis and gluconeogenesis ${ }^{15,19}$. With prolonged exercise, liver glucose output may fall below muscle glucose uptake ${ }^{15}$, thus resulting in hypoglycaemia that can be prevented by carbohydrate ingestion $^{20}$.

An increase in adipose tissue lipolysis supports the progressive increase in plasma fatty acid uptake and oxidation ${ }^{21}$, but because lipolysis exceeds uptake and oxidation, plasma fatty acid levels increase. Inhibition of adipose tissue lipolysis increases the reliance on both muscle glycogen and IMTG but has little effect on muscle glucose uptake ${ }^{17}$. The importance of IMTG oxidation during exercise has been a matter of debate, and results in the literature may be influenced by differences in individuals' training status, sex, fibre-type distribution and resting IMTG stores ${ }^{22}$. Nevertheless, IMTG does appear to be an important fuel source during exercise in trained individuals ${ }^{23}$.

Despite activation of the oxidative pathways in skeletal muscle during exercise, accelerated rates of glycolysis result in the production of lactate, which accumulates in muscle and blood, particularly at higher exercise intensities ${ }^{24}$. Although lactate was considered simply a metabolic waste product for many years, it is now recognized as an important substrate for oxidative metabolism, gluconeogenesis and muscle glycogenesis ${ }^{25-27}$, and as a signalling molecule mediating exercise adaptations and interorgan communication ${ }^{28-30}$. Glycerol is released into the circulation from contracting skeletal muscle and adipose tissue, as is alanine from muscle, and both can serve as liver gluconeogenic precursors during exercise ${ }^{15}$.

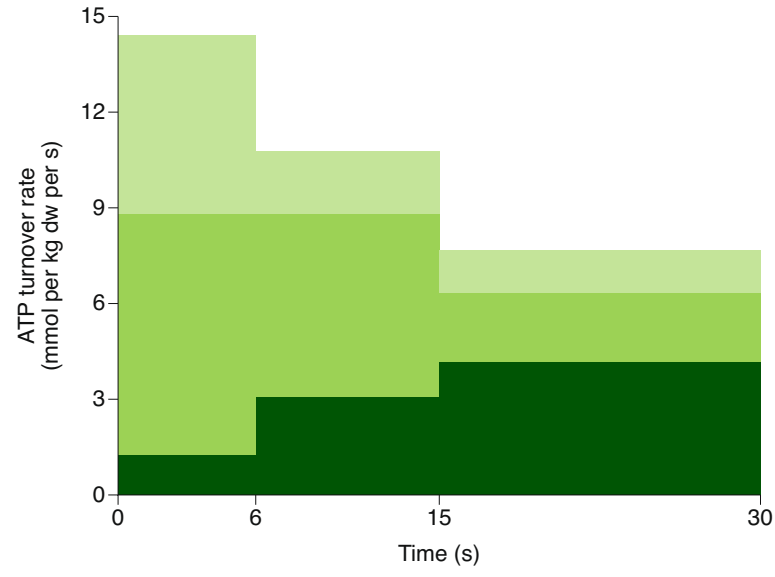

Fig. 1 | Muscle energy metabolism during intense exercise. Contributions of PCr (light green), glycolysis (medium green) and oxidative phosphorylation (dark green) to ATP turnover during maximal exercise. Muscle samples were obtained before and during $30 \mathrm{~s}$ of all-out cycling exercise. Dw, dry weight. Adapted with permission from ref. ${ }^{4}$, American Physiological Society.

Exercise increases protein turnover during exercise ${ }^{31}$, and although amino acids, notably the branched-chain amino acids, can be oxidized by contracting skeletal muscle, the contribution to overall ATP production is low. Under conditions of low carbohydrate availability, the contribution from amino acid metabolism is increased ${ }^{32,33}$, whereas endurance training results in decreased leucine oxidation ${ }^{34}$. Of greater importance are the postexercise increases in myofibrillar and mitochondrial protein synthesis that underpin the adaptations to acute and chronic endurance and resistance exercise ${ }^{35}$.

\section{Regulation of exercise metabolism}

General considerations. Because the increase in metabolic rate from rest to exercise can exceed 100-fold, well-developed control systems ensure rapid ATP provision and the maintenance of the ATP content in muscle cells. Numerous reviews have examined the regulation of skeletal muscle energy metabolism and the adaptations that occur with physical training ${ }^{1,36-38}$. Here, we briefly highlight some of the factors that regulate the remarkable ability of skeletal muscle to generate ATP during strenuous physical exercise (Fig. 4).

Intense short-term exercise. When very intense short-term exercise begins, all pathways associated with both anaerobic and aerobic ATP provision are activated (Box 1). However, the rates of ATP provision from the anaerobic sources, $\mathrm{PCr}$ and anaerobic glycolysis are much more rapid than those from aerobic pathways. $\mathrm{PCr}$ is a remarkable fuel source, because only one metabolic reaction is required to provide ATP (Box 1). The enzyme that catalyses this reaction, creatine phosphokinase, is highly abundant and is regulated by only the concentration of its substrates and products-a so-called 'near-equilibrium enzyme'. As soon as muscle contractions begin, and ATP is broken down and the concentration of free ADP increases, this reaction moves from left to right (Box 1), and ATP is regenerated in several milliseconds.

Simultaneously, cellular $\mathrm{Ca}^{2+}$ (and to some extent epinephrine from outside the cell) activates phosphorylase kinase, thereby transforming glycogen phosphorylase from its less active ' $b$ ' form to its more active 'a' form (covalent regulation; Fig. 4). Increases in ADP and AMP activate mainly phosphorylase a (through allosteric regulation), which breaks down glycogen; the products then combine 


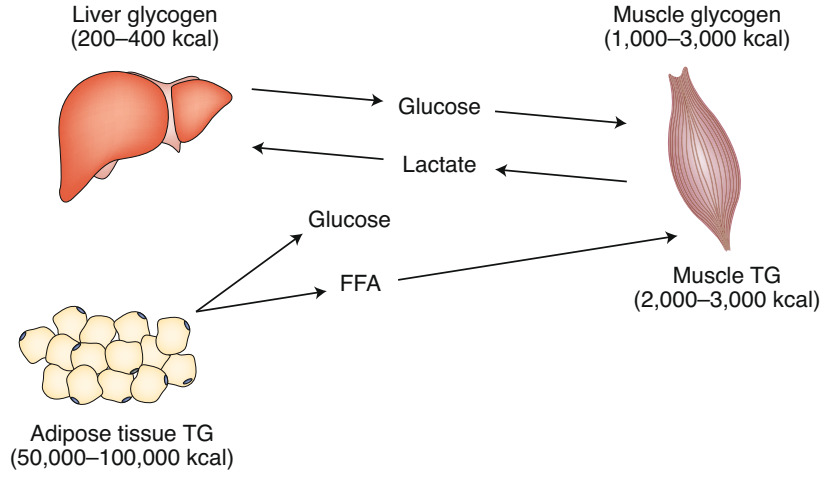

Fig. 2 | Intramuscular and extramuscular fuel sources for exercise metabolism. Major sources of carbohydrate in the muscle and liver and of fat in the muscle and adipose tissue during exercise. The estimated potential energy available from each fuel source is also provided. TG, triglyceride; FFA, free fatty acids.

with inorganic phosphate $\left(\mathrm{P}_{\mathrm{i}}\right)$, thus producing glucose 1-phosphate, glucose 6-phosphate and fructose 6-phosphate in the glycolytic pathway. Phosphorylase is considered a 'non-equilibrium enzyme' because it is controlled by external factors and not just its substrates and products. The dual control by local factors associated with muscle contractions and epinephrine ${ }^{39}$, and the combination of covalent and allosteric regulation explain how the flux through phosphorylase can increase from very low at rest to very high during intense exercise in only milliseconds.

The increases in the allosteric regulators ADP, AMP and $\mathrm{P}_{\mathrm{i}}$ (the by-products of ATP breakdown), and the substrate fructose 6-phosphate, activate the regulatory enzyme phosphofructokinase, and flux through the reactions of the glycolytic pathway continues with a net production of three ATP molecules and lactate formation (Fig. 4). Although there are more reactions in the glycolytic pathway than in PCr hydrolysis, the production of ATP through anaerobic glycolysis is also activated in milliseconds. Lactate accumulation can be measured in the muscle after only a 1-s contraction, and the contribution of anaerobic energy from $\mathrm{PCr}$ and anaerobic glycolysis is essentially equivalent after $6-10 \mathrm{~s}$ of intense exercise $\mathrm{e}^{4,24,40}$ (Fig. 1). The capacity of the PCr energy store is a function of its resting content ( $75 \mathrm{mmol}$ per kg dry muscle) and can be mostly depleted in 10-15 s of all-out exercise. The anaerobic glycolytic capacity is approximately threefold higher $(\sim 225 \mathrm{mmol}$ per kg dry muscle) in exercise lasting 30-90 s and is limited not by glycogen availability but instead by increasing intramuscular acidity.

Of note, aerobic ATP production is also activated during very intense exercise, and $70-100 \%$ of the $\mathrm{VO}_{2}$ max can be reached in an all-out 30-s sprint ${ }^{4,41}$ (Fig. 1). Whereas very little aerobic energy is provided in the first $5-10 \mathrm{~s}, \sim 50 \%$ of the energy contribution in the last $5 \mathrm{~s}$ of a $30-\mathrm{s}$ sprint is aerobic ${ }^{4}$. During the transition from rest to intense exercise, the substrate for increased aerobic ATP production is also muscle glycogen, and a small amount of the produced pyruvate is transferred into the mitochondria, where it is used to produce acetyl-CoA and the reducing equivalent $\mathrm{NADH}$ in the pyruvate dehydrogenase $(\mathrm{PDH})$ reaction. $\mathrm{PDH}$ is also under covalent control, existing in an inactive form at rest and transitioning to an active form via $\mathrm{Ca}^{2+}$ during exercise. The influence of $\mathrm{Ca}^{2+}$, with help from pyruvate, keeps the appropriate amount of the enzyme in the active form, despite increases in acetyl-CoA that would normally inactivate the enzyme at rest $^{42}$ (Box 2).

Dual-stage control of metabolism. The previous discussion supports the concept of dual-stage control in skeletal muscle metabolism: the first stage is 'gross control' by $\mathrm{Ca}^{2+}$ (and possibly epinephrine), which activates key regulatory enzymes, and the second stage, 'fine-tuning control' subsequently adjusts the production of ATP to the actual ATP demand (feedback from ADP, AMP, $\mathrm{P}_{\mathrm{i}}$ and many other factors at specific enzymes). Gross control could be called early-warning or feed-forward control, because the $\mathrm{Ca}^{2+}-$ which is released from the sarcoplasmic reticulum and binds troponin, thus allowing cross-bridge movement, and contraction-also activates many key steps in the regulation of metabolic pathways using carbohydrates and fat to produce energy. The feedback from the 'fine-tuners' of metabolism is well suited for second-stage regulation, because these molecules accumulate as a direct function of ATP use in contracting skeletal muscle ${ }^{42}$.

Molecular signalling and metabolic regulation. The many signals generated in contracting skeletal muscle during exercise $\left(\mathrm{Ca}^{2+} ; \mathrm{ADP}, \mathrm{AMP}, \mathrm{P}_{\mathrm{i}}\right.$ and altered energy charge; cyclic AMP after $\beta$-adrenergic activation; and nitric oxide (NO), reactive oxygen species (ROS), tension and temperature) not only have direct effects on metabolic pathways but also activate numerous kinases and signalling cascades. Much attention has been focused on the kinases that are sensitive to changes in intramuscular $\mathrm{Ca}^{2+}$ concentrations, energy charge and plasma epinephrine concentrations ${ }^{43-47}$. An important role of $5^{\prime}$-AMP-activated protein kinase (AMPK), a sensor of muscle energy charge and glycogen levels, in muscle glucose uptake and fat oxidation during exercise would be teleologically attractive but appears not to be the case ${ }^{48}$. Instead, AMPK activation during exercise may be functionally more important for the postexercise changes in muscle metabolism and insulin sensitivity, and for mediating some of the key adaptive responses to exercise in skeletal muscle, such as mitochondrial biogenesis and enhanced glucose transporter (GLUT) 4 expression.

Considerable redundancy and complex spatial and temporal interactions among multiple intramuscular signalling pathways are likely to occur during exercise. Indeed, recent studies performing phosphoproteomic analyses of human and rodent skeletal muscle before and after exercise and/or muscle contraction have identified more than 1,000 exercise-regulated phosphosites on more than 550 proteins, many of which have unknown function ${ }^{49,50}$. Further studies on L6 myoblasts have demonstrated that coadministration of $\mathrm{Ca}^{2+}$ and $\beta$-adrenergic agonists closely recapitulates the phosphoproteomic signature observed in exercise and/or muscle contraction ${ }^{51}$, thus again emphasizing the key roles of $\mathrm{Ca}^{2+}$ and epinephrine during exercise. In future studies, these approaches should provide new insights into the molecular regulation of skeletal muscle energy metabolism during exercise.

Aerobic exercise. In examining energy production during endurance exercise at intensities below $100 \% \mathrm{VO}_{2}$ max, aerobic ATP generation dominates. In this situation, there is time to mobilize fat and carbohydrate substrates from sources in the muscle as well as from the adipose tissue and liver (Fig. 2). The muscles still rely on anaerobic energy for the initial 1-2 min when transitioning from rest to an aerobic power output, but then aerobic metabolism dominates. To produce the required ATP, the respiratory or electron-transport chain in the mitochondria requires the following substrates: reducing equivalents in the form of $\mathrm{NADH}$ and $\mathrm{FADH}_{2}$, free ADP, $\mathrm{P}_{\mathrm{i}}$ and $\mathrm{O}_{2}$ (Fig. 4). The respiratory and cardiovascular systems ensure the delivery of $\mathrm{O}_{2}$ to contracting muscles, and the by-products of ATP utilization in the cytoplasm ( $\mathrm{ADP}$ and $\mathrm{P}_{\mathrm{i}}$ ) are transported back into the mitochondria for ATP resynthesis. The processes that move ATP out of the mitochondria and ADP and $\mathrm{P}_{\mathrm{i}}$ back into the mitochondria are being intensely studied and appear to be more heavily regulated than previously thought ${ }^{52,53}$. In the presence of ample $\mathrm{O}_{2}$ and $\mathrm{ADP}$ and $\mathrm{P}_{\mathrm{i}}$ in the mitochondria, the increase in ADP concentration with exercise is believed to activate the respiratory chain to produce $\mathrm{ATP}^{54}$. 


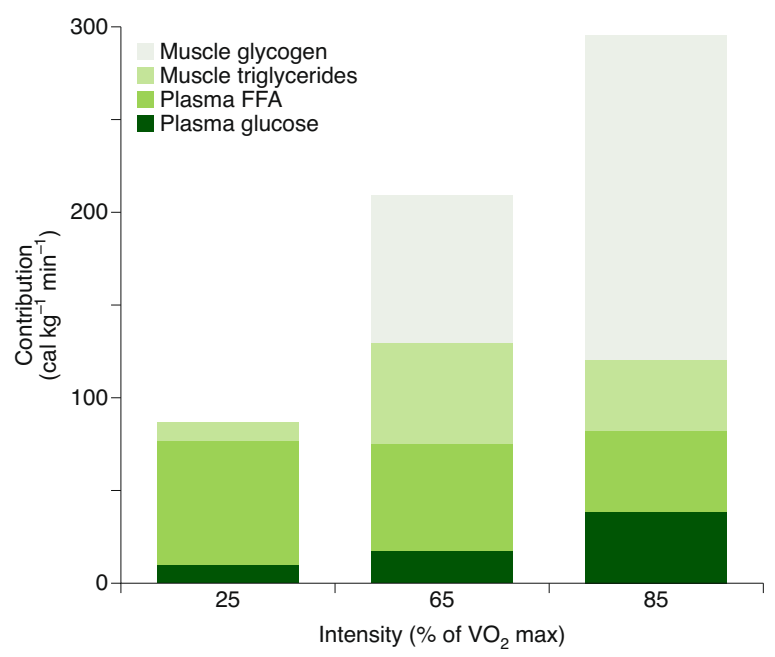

Fig. 3 | Relative contributions of carbohydrate and fat fuel sources during exercise. Trained cyclists exercised at increasing intensities, and the relative contributions of fuels for contracting skeletal muscle were measured with indirect calorimetry and tracer methods. An increasing contribution of carbohydrate fuels, notably muscle glycogen, is observed at higher exercise intensities. FFA, free fatty acids; cal, calorie. Adapted with permission from ref. ${ }^{11}$, American Physiological Society.

In terms of the metabolic pathways, the tricarboxylic acid (TCA) cycle in the mitochondria specializes in producing reducing equivalents and accepts acetyl-CoA mainly from carbohydrate and fat (and other fuels) to do so. During aerobic exercise, increasing mitochondrial $\mathrm{Ca}^{2+}$ concentrations activate the isocitrate and $\alpha$-ketoglutarate dehydrogenase enzymes in the TCA cycle (Fig. 4). Substrate accumulation and local regulators fine-tune the flux through the dehydrogenases, and a third enzyme, citrate synthase, controls TCA-cycle flux. $\mathrm{Ca}^{2+}$ also activates glycogen phosphorylase and $\mathrm{PDH}$, but the glycolytic flux needed to supply sufficient acetyl-CoA from carbohydrate and ultimately aerobic ATP production is much lower than that during sprint exercise, owing to smaller increases in the fine-tuners of metabolism, ADP, AMP and $\mathrm{P}_{\mathrm{i}}$. Additional NADH is produced both in the glycolytic pathway, after which it is shuttled from the cytoplasm into the mitochondria, and in the PDH reaction, which occurs in the mitochondria.

Simultaneously, $\mathrm{Ca}^{2+}$ and epinephrine activate the key enzymes regulating IMTG degradation-adipose triglyceride lipase and hormone-sensitive lipase-and fatty acids are provided in the cytoplasm ${ }^{55,56} \cdot \mathrm{Ca}^{2+}$ also contributes to the movement of glucose and fatty acids into the muscle cells from the blood, by using transport proteins at the sarcolemma and transverse tubules. The transport protein GLUT4 facilitates the influx of glucose into cells, and increases in glucose delivery, secondary to enhanced muscle blood flow, and intramuscular glucose metabolism ensure that the gradient for glucose diffusion is maintained during exercise ${ }^{57}$. Translocation of GLUT4 is a fundamental event in exercise-induced muscle glucose uptake, and its regulation has been well studied ${ }^{58}$. Early research focused on the potential roles of $\mathrm{Ca}^{2+}$ and AMPK, but more recently $\mathrm{NO}$ and ROS have been implicated, and a key role of the small Rho family GTPase Rac1 has been suggested ${ }^{58}$.

Transport proteins for fat are also translocated to the muscle membrane (mainly plasma membrane fatty acid-binding protein) and mitochondrial membranes (mainly fatty acid translocase (FAT, also known as CD36)), where they transport fatty acids into cells and mitochondria ${ }^{59,60}$. The fatty acids that are transported into the cytoplasm of the cell and released from IMTG must also be transported across the mitochondrial membranes with the help of the carnitine palmitoyl transferase (CPT) I system and fat-transport proteins, mainly FAT $(\mathrm{CD} 36)^{61,62}$. Once inside the mitochondria, fat enters the $\beta$-oxidation pathway, which produces acetyl-CoA and reducing equivalents ( $\mathrm{NADH}$ and $\mathrm{FADH}_{2}$ ), and the long-chain nature of fatty acids results in generation of large amounts of aerobic ATP (Box 1).

At moderate exercise intensities of $\sim 50-70 \% \mathrm{VO}_{2}$ max, both fat and carbohydrate contribute substrate from stores inside and outside the muscle (Fig. 3). However, during the endurance events common in the Olympics, exercise intensities are higher and approach 80-100\% $\mathrm{VO}_{2}$ max. In these situations, fuel use shifts to carbohydrate, and reliance on fat is decreased (Fig. 3). From a performance perspective, this fuel shift makes sense, because the energy yield from carbohydrate aerobic ATP production is approximately $7 \%$ more efficient than that from fat. However, if the endurance event is extended, the liver and skeletal muscle glycogen stores may become exhausted, thereby requiring athletes to slow down. Researchers have now identified several sites where fat metabolism is downregulated at high aerobic exercise intensities, including decreased fatty acid release from adipose tissue and therefore less fatty acid transport into cells; decreased activation of hormone-sensitive lipase and possibly adipose triglyceride lipase; less IMTG breakdown; and inhibition of CPT I activity as a result of small decreases in muscle $\mathrm{pH}$, decreased CPT I sensitivity to carnitine and possibly low levels of cytoplasmic carnitine-reducing mitochondrial-membrane transport ${ }^{37,63}$.

Carbohydrate is the fuel for high-intensity exercise. One aspect of metabolism that becomes apparent for Olympic calibre athletes is the value of carbohydrate as a fuel for high-intensity exercise-whether in the highly aerobic domain $\left(\sim 80-100 \% \mathrm{VO}_{2} \max \right)$, during sprinting (typically referred to as $\% \mathrm{VO}_{2}$ max above $100 \%$ ) or a combination of the two in stop-and-go individual and team sports $^{9,64}$. In many team sports, a high aerobic ability is needed for players to move about the field or playing surface, whereas sprints (and anaerobic ATP), as dictated by the game, are added to the contribution of aerobic ATP. This scenario is repeated many times during a game, and carbohydrate provides most of the aerobic fuel and much of the anaerobic fuel.

Unsurprisingly, almost every regulatory aspect of carbohydrate metabolism is designed for rapid provision of ATP. Carbohydrate is the only fuel that can be used for both aerobic and anaerobic ATP production, and both systems are activated very quickly during transitions from rest to exercise and from one power output to a higher power output. Carbohydrate can also provide all the fuel during exercising at a power output that elicits $\sim 100 \% \mathrm{VO}_{2}$ max, and it is a more efficient fuel than fat, as stated above. Fat-derived ATP production is designed to provide a 'helper fuel' during exercise, with a maximum amount of energy at power outputs of $\sim 60-65 \% \mathrm{VO}_{2} \mathrm{max}^{65}$. In addition, the processes that provide fatty acids to the muscles and the pathways that metabolize fat and provide ATP in muscles are slower than the carbohydrate pathways. However, in events requiring long periods of exercise at submaximal power outputs, fat can provide energy for long periods of time and has a much larger ATP-generating capacity than carbohydrate. Fat oxidation also contributes energy in recovery from exercise or rest periods between activity.

Phosphocreatine resynthesis. Another important aspect of metabolism in stop-and-go sports is the ability to rapidly resynthesize $\mathrm{PCr}$ when the exercise intensity falls to low levels or athletes rest. In these situations, continued aerobic production of ATP fuels the regeneration of PCr such that it can be completely recovered in 60-120 s $\left(\right.$ ref. $\left.{ }^{6}\right)$. This production is extremely important for the ability to repeatedly sprint in stop-and-go or intermittent sports. Recovery from prolonged sprinting (20-120s) and sustained high glycolytic flux is slower, because the associated muscle acidity requires minutes, not seconds, to recover and can limit performance ${ }^{4,40}$. 


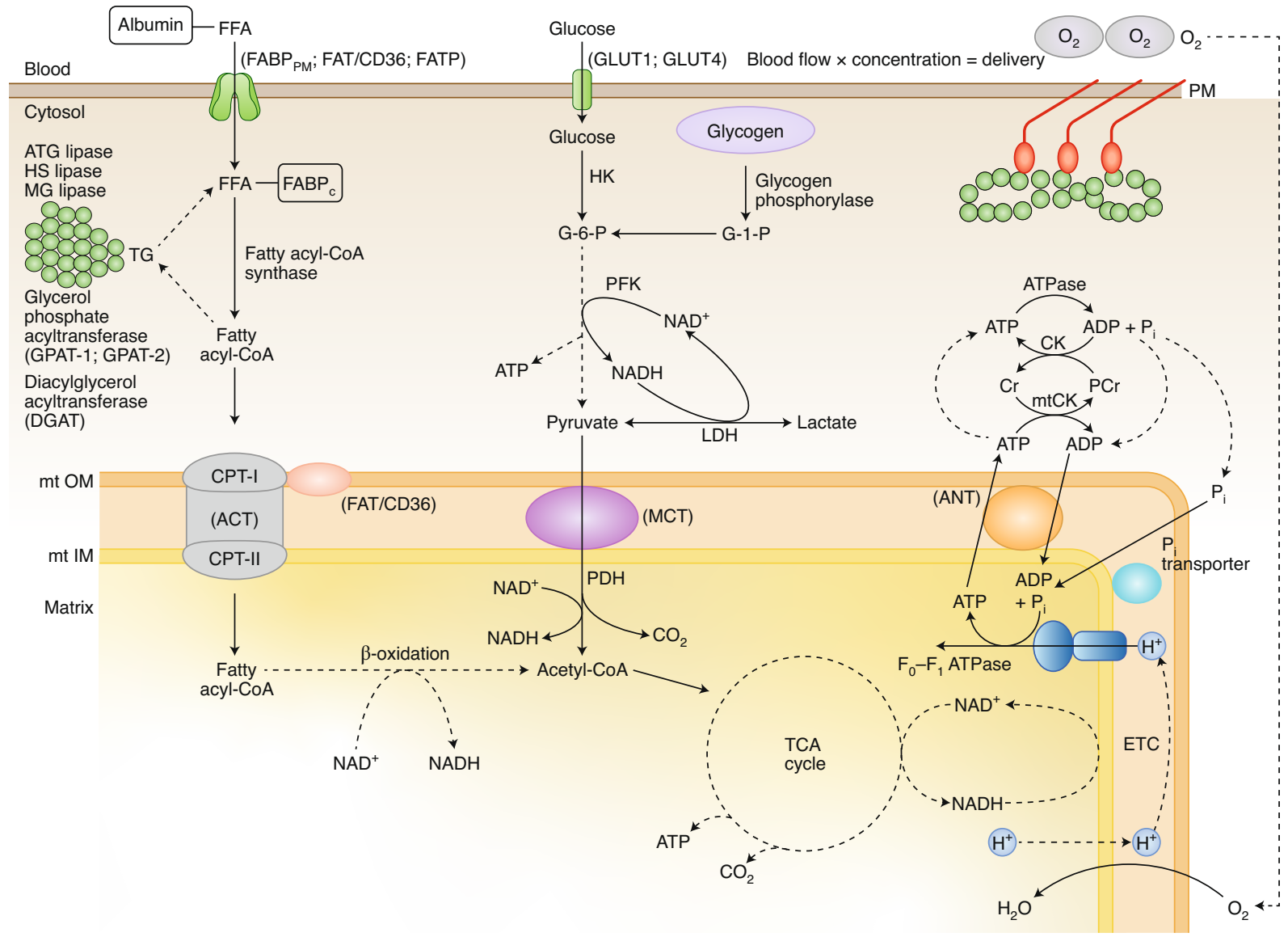

Fig. 4 | Key metabolic pathways in contracting skeletal muscle during exercise. The utilization of extramuscular and intramuscular carbohydrate and fat fuels, along with the major sites of regulation at key enzymes and transport proteins. Interactions between anaerobic and aerobic pathways, and between carbohydrate and fat, ensure the ATP supply for contracting skeletal muscle. FFA, free fatty acids; PM, plasma membrane; $F_{A B P} P_{P_{M}}$, plasma membrane fatty acid-binding protein; FATP, fatty acid transport protein; ATG, adipose triglyceride; $H S$, hormone sensitive; $M G$, monoglyceride; TG, triglyceride; FABP ${ }_{c^{\prime}}$ cytoplasmic fatty acid binding protein; $\mathrm{HK}$, hexokinase; PFK, phosphofructokinase; $\mathrm{LDH}$, lactate dehydrogenase; $\mathrm{Cr}$, creatine; mtCK, mitochondrial creatine kinase; $\mathrm{mt} \mathrm{OM}$ and $\mathrm{mt} \mathrm{IM}$, outer and inner mitochondrial membrane; $\mathrm{ACT}$, acyl-CoA transferase; $\mathrm{MCT}$, monocarboxylase transporter; ANT, adenine transport; $\mathrm{PDH}$, pyruvate dehydrogenase; ETC, electron-transport chain.

\section{Box 2 | Metabolic control during exercise}

A central concept in the rapid activation of metabolic pathways at the onset of exercise is how the factors that regulate metabolism at rest are immediately overridden by the more powerful ('heavy hitter') regulatory factors that take control and dominate during exercise. A good example is the enzyme $\mathrm{PDH}$, which is kept in inactive form by resting levels of acetyl-CoA and NADH. When exercise begins, the exercise regulators $\mathrm{Ca}^{2+}$ and pyruvate increase the conversion of the enzyme to the active form and, as long as substrates (pyruvate, $\mathrm{CoA}$ and $\mathrm{NAD}^{+}$) are present, flux occurs despite increases in acetyl-CoA and possibly $\mathrm{NADH}$, which would normally keep PDH inactive at rest. The power of these resting regulators is weak compared with that of the heavy hitters in exercise.

Other potential fuels. Importantly, other fuels can provide aerobic energy in cells during exercise, including amino acids, acetate, medium-chain triglycerides, and the ketones $\beta$-hydroxybutyrate and acetoacetic acid. Although these fuels can be used to spare the use of fat and carbohydrate in some moderate-intensity exercise situations, they lack the rate of energy provision needed to fuel intense aerobic exercise, because the metabolic machinery for these fuels is not designed for rapid energy provision. The provision of the fuel into the muscle may be slow, and the amount stored or available in the muscles and/or the enzyme content controlling the use of these fuels may be low. Alternative fuels cannot match carbohydrate in terms of the rate of aerobic energy provision ${ }^{9}$, and these fuels cannot be used to produce anaerobic energy in the absence of oxygen.

Sex differences in metabolism. Sex may have roles in the regulation of skeletal muscle metabolism. Males and females are often assumed to respond similarly to acute exercise and exercise training, but most of the work cited in this Review involved male participants. Clear differences exist between males and females-including haemoglobin concentrations, muscle mass and reproductive-hormone levels-and have been shown to affect metabolism and exercise performance, thus making perfect comparisons between males and females very difficult. The potential sex differences in metabolism are briefly mentioned in Box 3, and more detailed discussion can be found in a review by Kiens ${ }^{22}$.

\section{Targeting metabolism for ergogenic benefit}

General considerations. Sports performance is determined by many factors but is ultimately limited by the development of fatigue, such that the athletes with the greatest fatigue resistance often succeed. However, there can be a fine line between glory and catastrophe, and the same motivation that drives athletes to victory can 


\section{Box 3 | Sex differences in exercise metabolism}

One issue in the study of the regulation of exercise metabolism in skeletal muscle is that much of the available data has been derived from studies on males. Although the major principles controlling the regulation of metabolism appear to hold true for both females and males, some differences have been noted. Although one might argue that completely matching males and females is impossible when studying metabolism, early work with well-trained track athletes has reported no differences in skeletal muscle enzyme activity, fibre-type composition and fat oxidation between men and women ${ }^{176,177}$. However, more recent work has reported that a larger percentage of whole-body fuel use is derived from fat in females exercising at the same relative submaximal intensity, and this effect is likely to be related to circulating oestrogen levels ${ }^{178-183}$. Females have a higher proportion of type I fibres, lower maximal capacity of glycolytic enzymes, and greater reliance on IMTG during exercise than males, effects that may be related to females' higher IMTG concentrations in type I fibres ${ }^{22}$. In addition, supplementation with oestrogen in males decreases carbohydrate oxidation and increases fat oxidation during endurance exercise ${ }^{184}$. These results suggest that females may be better suited to endurance exercise than males.

Another area that has been investigated is the effects of menstrual phase and menstrual status on the regulation of skeletal muscle metabolism. Generally, studies examining exercise in the luteal and follicular phases have reported only minor or no changes in fat and carbohydrate metabolism at various exercise intensities ${ }^{185-188}$. Additional work examining the regulation of metabolism in well-trained female participants in both phases of the menstrual cycle, and with varied menstrual cycles, during exercise at the high aerobic and supramaximal intensities commensurate with elite sports, is warranted.

at times push them beyond their limits. Fatigue is the result of a complex interplay among central neural regulation, neuromuscular function and the various physiological processes that support skeletal muscle performance ${ }^{1}$. It manifests as a decrease in the force or power-producing capacity of skeletal muscle and an inability to maintain the exercise intensity needed for ultimate success.

Over the years, considerable interest has been placed on the relative importance of central neural and peripheral muscle factors in the aetiology of fatigue. The great Finnish runner and nine-time Olympic champion Paavo Nurmi once said, "Mind is everything; muscle, pieces of rubber. All that I am, I am because of my mind." Numerous exercise-induced changes occur within the central nervous system and spinal motor outflow that contribute to fatigue ${ }^{67}$, along with many intramuscular factors that decrease force and power generation ${ }^{68}$, and interactions occur between both sites ${ }^{69}$.

Perhaps the two major interventions used to enhance fatigue resistance are regular training and nutrition ${ }^{70}$, and the interactions between them have been recognized ${ }^{71}$. We briefly review the effects of training and nutrition on skeletal muscle energy metabolism and exercise performance, with a focus on substrate availability and metabolic end products. In relation to dietary supplements, we have limited our discussion to those that have been reasonably investigated for efficacy in human participants ${ }^{72}$.

Training. Regular physical training is an effective strategy for enhancing fatigue resistance and exercise performance, and many of these adaptations are mediated by changes in muscle metabolism and morphology. High-intensity interval training increases the capacity for anaerobic energy production ${ }^{73}$, enhanced tolerance of metabolic acidosis due to increased muscle buffer capacity ${ }^{74,75}$ and improved ionic regulation, notably $\mathrm{K}^{+}$balance $^{76}$. Such training is also associated with the cardiovascular and metabolic benefits often observed with traditional endurance training ${ }^{77}$. One hallmark adaptation to endurance exercise training is increased oxygen-transport capacity, as measured by $\mathrm{VO}_{2} \max ^{78}$, thus leading to greater fatigue resistance and enhanced exercise performance ${ }^{79}$. The other is enhanced skeletal muscle mitochondrial density ${ }^{80}$, a major factor contributing to decreased carbohydrate utilization and oxidation and lactate production ${ }^{81,82}$, increased fat oxidation and enhanced endurance exercise performance ${ }^{83}$. The capacity for muscle carbohydrate oxidation also increases, thereby enabling maintenance of a higher power output during exercise and enhanced performance ${ }^{84}$. Finally, resistance training results in increased strength, neuromuscular function and muscle mass ${ }^{85}$, effects that can be potentiated by nutritional interventions, such as increased dietary protein intake ${ }^{71}$.

Creatine supplementation. The observation that short-term ingestion of creatine monohydrate increases total skeletal muscle creatine content by $20-25 \%$ and PCr levels by $10-15 \%$ (refs. ${ }^{86,87}$ ) has led to further studies demonstrating the ergogenic benefits of creatine supplementation for repeated high-intensity exercise performance ${ }^{88,89}$. The improved performance is believed to be due to enhanced ATP resynthesis during exercise as a result of increased $\mathrm{PCr}$ availability. Some evidence also indicates that creatine supplementation may increase muscle mass and strength during resistance training ${ }^{90}$. No major adverse effects of creatine supplementation have been observed in the short term, but long-term studies are lacking. Creatine remains one of the most widely used sports-related dietary supplements.

Carbohydrate loading. The importance of carbohydrate for performance in strenuous exercise has been recognized since the early nineteenth century, and for more than 50 years, fatigue during prolonged strenuous exercise has been associated with muscle glycogen depletion $^{13,91}$. Muscle glycogen is critical for ATP generation and supply to all the key ATPases involved in excitation-contraction coupling in skeletal muscle ${ }^{92}$. Recently, prolonged exercise has been shown to decrease glycogen in rodent brains, thus suggesting the intriguing possibility that brain glycogen depletion may contribute to central neural fatigue ${ }^{93}$.

Increasing dietary carbohydrate intake before exercise increases muscle glycogen availability (so-called 'glycogen loading') and increases endurance exercise capacity and performance in events longer than $\sim 60-90 \mathrm{~min}$ (refs. ${ }^{94,95}$ ). Muscle glycogen availability may also be important for high-intensity exercise performance ${ }^{96}$. Blood glucose levels decline during prolonged strenuous exercise, because the liver glycogen is depleted, and increased liver gluconeogenesis is unable to generate glucose at a rate sufficient to match skeletal muscle glucose uptake. Maintenance of blood glucose levels at or slightly above pre-exercise levels by carbohydrate supplementation maintains carbohydrate oxidation, improves muscle energy balance at a time when muscle glycogen levels are decreased and delays fatigue $e^{20,97,98}$. Glucose ingestion during exercise has minimal effects on net muscle glycogen utilization ${ }^{97,99,100}$ but increases muscle glucose uptake and markedly decreases liver glucose output $^{100,101}$, because the gut provides most glucose to the bloodstream. Importantly, although carbohydrate ingestion delays fatigue, it does not prevent fatigue, and many factors clearly contribute to fatigue during prolonged strenuous exercise.

Because glucose is the key substrate for the brain, central neural fatigue may develop during prolonged exercise as a consequence of hypoglycaemia and decreased cerebral glucose uptake ${ }^{102}$. Carbohydrate ingestion exerts its benefit by increasing cerebral glucose uptake and maintaining central neural drive ${ }^{102}$. Ammonia $\left(\mathrm{NH}_{3}\right)$ is produced within contracting skeletal muscle by the breakdown of ATP and/or amino acids and is released into the 
circulation, thereby increasing plasma $\mathrm{NH}_{3}$ levels during exercise. $\mathrm{NH}_{3}$ can cross the blood-brain barrier and has the potential to affect central neurotransmitter levels and central neural fatigue. Of note, carbohydrate ingestion attenuates muscle and plasma $\mathrm{NH}_{3}$ accumulation during exercise ${ }^{103}$, another potential mechanism through which carbohydrate ingestion exerts its ergogenic effect. Enhanced exercise performance has also been observed from simply having carbohydrate in the mouth, an effect that has been linked to activation of brain centres involved in motor control ${ }^{104}$.

High-fat diets. Increased plasma fatty acid availability decreases muscle glycogen utilization and carbohydrate oxidation during exercise $^{105-107}$. High-fat diets have also been proposed as a strategy to decrease reliance on carbohydrate and improve endurance performance. An early study has observed maintained exercise capacity at $\sim 60-65 \% \mathrm{VO}_{2}$ max with a high-fat diet that induced ketosis, despite a marked decrease in muscle glycogen use ${ }^{108}$; however, the exercise intensity studied was one that can be largely supported by fat oxidation and is lower than those seen during competitive endurance events. Other studies have demonstrated increased fat oxidation and lower rates of muscle glycogen use and carbohydrate oxidation after adaptation to a short-term high-fat diet, even with restoration of muscle glycogen levels, but no effect on endurance exercise performance ${ }^{109,110}$. If anything, high-intensity exercise performance is impaired on the high-fat diet ${ }^{110}$, apparently as a result of an inability to fully activate glycogenolysis and PDH during intense exercise $^{111}$. Furthermore, a high-fat diet has been shown to impair exercise economy and performance in elite race walkers ${ }^{112}$.

A related issue with high-fat, low carbohydrate diets is the induction of nutritional ketosis after $2-3$ weeks. This so-called ketogenic diet ( $<50 \mathrm{~g}$ carbohydrate per day) has been suggested to be useful for increasing exercise performance ${ }^{113}$. However, when this diet is adhered to for 3 weeks, and the concentrations of ketone bodies are elevated, a decrease in performance has been observed in elite race walkers $^{112}$. The rationale for following this dietary approach to optimize performance has been called into question ${ }^{114}$.

Although training on a high-fat diet appears to result in suboptimal adaptations in previously untrained participants ${ }^{115}$, some studies have reported enhanced responses to training with low carbohydrate availability in well-trained participants ${ }^{116,117}$. Over the years, endurance athletes have commonly undertaken some of their training in a relatively low-carbohydrate state. However, maintaining an intense training program is difficult without adequate dietary carbohydrate intake ${ }^{118}$. Furthermore, given the heavy dependence on carbohydrate during many of the events at the Olympics ${ }^{9}$, the most effective strategy for competition would appear to be one that maximizes carbohydrate availability and utilization.

Ketone esters. Nutritional ketosis can also be induced by the acute ingestion of ketone esters, which has been suggested to alter fuel preference and enhance performance ${ }^{119}$. The metabolic state induced is different from diet-induced ketosis ${ }^{120}$ and has the potential to alter the use of fat and carbohydrate as fuels during exercise. However, published studies on trained male athletes from at least four independent laboratories to date do not support an increase in performance. Acute ingestion of ketone esters has been found to have no effect on $5-\mathrm{km}$ and $10-\mathrm{km}$ trial performance ${ }^{121,122}$, or performance during an incremental cycling ergometer test ${ }^{123}$. A further study has reported that ketone ester ingestion decreases performance during a $31.7-\mathrm{km}$ cycling time trial in professional cyclists ${ }^{124}$. The rate of ketone provision and metabolism in skeletal muscle during high-intensity exercise appears likely to be insufficient to substitute for the rate at which carbohydrate can provide energy.

Caffeine. Early work on the ingestion of high doses of caffeine (6-9 mg caffeine per $\mathrm{kg}$ body mass) $60 \mathrm{~min}$ before exercise has indicated enhanced lipolysis and fat oxidation during exercise, decreased muscle glycogen use and increased endurance performance in some individuals ${ }^{125-127}$. These effects appear to be a result of caffeine-induced increases in catecholamines, which increase lipolysis and consequently fatty acid concentrations during the rest period before exercise. After exercise onset, these circulating fatty acids are quickly taken up by the tissues of the body (10-15 min), fatty acid concentrations return to normal, and no increases in fat oxidation are apparent. In addition, a direct examination of leg fuel oxidation during $60 \mathrm{~min}$ of exercise at $70 \% \mathrm{VO}_{2} \max$ has revealed no effect of caffeine ingestion (6 mg per kg body mass) on fat oxidation $^{128}$. Importantly, the ergogenic effects of caffeine have also been reported at lower caffeine doses ( $\sim 3 \mathrm{mg}$ per $\mathrm{kg}$ body mass) during exercise and are not associated with increased catecholamine and fatty acid concentrations and other physiological alterations during exercise $^{129,130}$.

This observation suggests that the ergogenic effects are mediated not through metabolic events but through binding to adenosine receptors in the central and peripheral nervous systems. Caffeine has been proposed to increase self-sustained firing, as well as voluntary activation and maximal force in the central nervous system, and to decrease the sensations associated with force, pain and perceived exertion or effort during exercise in the peripheral nervous system $^{131,132}$. The ingestion of low doses of caffeine is also associated with fewer or none of the adverse effects reported with high caffeine doses (anxiety, jitters, insomnia, inability to focus, gastrointestinal unrest or irritability). Contemporary caffeine research is focusing on the ergogenic effects of low doses of caffeine ingested before and during exercise in many forms (coffee, capsules, gum, bars or gels), and a dose of $\sim 200 \mathrm{mg}$ caffeine has been argued to be optimal for exercise performance ${ }^{133,134}$.

Carnitine. The potential of supplementation with L-carnitine has received much interest, because this compound has a major role in moving fatty acids across the mitochondrial membrane and regulating the amount of acetyl-CoA in the mitochondria. The need for supplemental carnitine assumes that a shortage occurs during exercise, during which fat is used as a fuel. Although this outcome does not appear to occur during low-intensity and moderate-intensity exercise, free carnitine levels are low in high-intensity exercise and may contribute to the downregulation of fat oxidation at these intensities. However, oral supplementation with carnitine alone leads to only small increases in plasma carnitine levels and does not increase the muscle carnitine content ${ }^{135}$.

However, over the past 15 years, a series of studies have shown that the oral ingestion of L-carnitine $(\sim 2 \mathrm{~g})$ and large amounts of carbohydrate ( $\sim 80 \mathrm{~g}$, to generate high insulin levels) twice per day can increase muscle carnitine uptake and produce increases of $\sim 20 \%$ over a 3- to 6-month period ${ }^{136-138}$. An insulin level of $\sim 70 \mathrm{mU} \mathrm{l}^{-1}$ is required to promote carnitine uptake by the muscle ${ }^{139}$. Although the consumption of high doses of carbohydrate twice per day for a long period is of some concern, an $11 \%$ increase has been observed in a $30-\mathrm{min}$ 'all-out' exercise performance test ${ }^{137}$. However, to date, there is no evidence that carnitine supplementation can improve performance during the higher exercise intensities common to endurance sports.

Nitrate. NO is an important bioactive molecule with multiple physiological roles within the body. It is produced from L-arginine via the action of nitric oxide synthase and can also be formed by the nonenzymatic reduction of nitrate and nitrite. The observation that dietary nitrate decreases the oxygen cost of exercise ${ }^{140}$ has stimulated interest in the potential of nitrate, often ingested in the form of beetroot juice, as an ergogenic aid during exercise. Indeed, several studies have observed enhanced exercise performance associated with lower oxygen cost and increased muscle efficiency after beetroot-juice ingestion ${ }^{141-143}$. The effect of nitrate supplementation 
appears to be less apparent in well-trained athletes ${ }^{144,145}$, although results in the literature are varied ${ }^{146}$. Dietary nitrate supplementation may have beneficial effects through an improvement in excitation-contraction coupling ${ }^{147,148}$, because supplementation with beetroot juice does not alter mitochondrial efficiency in human skeletal muscle ${ }^{149}$, and the results with inorganic nitrate supplementation have been equivocal ${ }^{150,151}$.

Alkalosis and buffering. With the breakdown of ATP, PCr and glycogen in contracting skeletal muscle during intense exercise, marked increases in $\mathrm{Mg}^{2+}, \mathrm{ADP}, \mathrm{P}_{\mathrm{i}}$, lactate and $\mathrm{H}^{+}$occur and have been associated with fatigue at various steps within the excitation-contraction pathway ${ }^{68}$. Lactate is not thought to have a major negative effect on force and power generation and, as mentioned earlier, is an important metabolic intermediate and signalling molecule. Of greater importance is the acidosis arising from increased muscle metabolism and strong ion fluxes. Increased $\mathrm{H}^{+}$concentrations are widely believed to interfere with muscle force and power production $^{41}$, although the results of studies in single muscle fibres and isolated muscle preparations are equivocal ${ }^{68}$. In humans, acidosis does not appear to impair maximal isometric-force production, but it does limit the ability to maintain submaximal force output $^{152}$, thus suggesting an effect on energy metabolism and ATP generation ${ }^{153}$. Ingestion of oral alkalizers, such as bicarbonate, is often associated with increased high-intensity exercise performance ${ }^{154,155}$, partly because of improved energy metabolism ${ }^{156}$ and ionic regulation $^{157,158}$. As previously mentioned, high-intensity exercise training increases muscle buffer capacity ${ }^{74,75}$. A major determinant of the muscle buffering capacity is carnosine content, which is higher in sprinters and rowers than in marathon runners or untrained individuals ${ }^{159}$. Ingestion of $\beta$-alanine increases muscle carnosine content and enhances high-intensity exercise performance ${ }^{160,161}$.

Antioxidants. During exercise, ROS, such as superoxide anions, hydrogen peroxide and hydroxyl radicals, are produced and have important roles as signalling molecules mediating the acute and chronic responses to exercise ${ }^{162}$. However, ROS accumulation at higher levels can negatively affect muscle force and power production and induce fatigue ${ }^{68,162}$. Exercise training increases the levels of key antioxidant enzymes (superoxide dismutase, catalase and glutathione peroxidase), and non-enzymatic antioxidants (reduced glutathione, $\beta$-carotene, and vitamins $\mathrm{C}$ and $\mathrm{E}$ ) can counteract the negative effects of ROS. Whether dietary antioxidant supplementation can improve exercise performance is equivocal ${ }^{163}$, although ingestion of $N$-acetylcysteine enhances muscle oxidant capacity and attenuates muscle fatigue during prolonged exercise ${ }^{164}$. Some reports have suggested that antioxidant supplementation may potentially attenuate skeletal muscle adaptation to regular exercise ${ }^{163,165,166}$. Overall, ROS may have a key role in mediating adaptations to acute and chronic exercise but, when they accumulate during strenuous exercise, may exert fatigue effects that limit exercise performance.

Hyperthermia. Because the mechanical efficiency during exercise is $\sim 20 \%$, most of the energy generated from metabolism is released as heat, which is dissipated by the evaporation of sweat and other heat-loss mechanisms. When the rate of heat production is high, such as during strenuous exercise, or heat loss is compromised by elevated environmental temperature and/or humidity, hyperthermia can develop and impair exercise performance via effects on central neural drive, cardiovascular function, and muscle metabolism and function ${ }^{167}$. The negative effects of hyperthermia are potentiated by sweating-induced fluid losses and dehydration ${ }^{168}$, particularly decreased skeletal muscle blood flow and increased muscle glycogen utilization during exercise in heat ${ }^{169}$. Increased plasma catecholamines and elevated muscle temperatures also accelerate muscle glycogenolysis during exercise in heat ${ }^{170-172}$. Strategies to minimize the negative effects of hyperthermia on muscle metabolism and performance include acclimation, pre-exercise cooling and fluid ingestion ${ }^{171,173-175}$.

\section{Conclusion and future perspectives}

To meet the increased energy needs of exercise, skeletal muscle has a variety of metabolic pathways that produce ATP both anaerobically (requiring no oxygen) and aerobically. These pathways are activated simultaneously from the onset of exercise to precisely meet the demands of a given exercise situation. Although the aerobic pathways are the default, dominant energy-producing pathways during endurance exercise, they require time (seconds to minutes) to fully activate, and the anaerobic systems rapidly (in milliseconds to seconds) provide energy to cover what the aerobic system cannot provide. Anaerobic energy provision is also important in situations of high-intensity exercise, such as sprinting, in which the requirement for energy far exceeds the rate that the aerobic systems can provide. This situation is common in stop-and-go sports, in which transitions from lower-energy to higher-energy needs are numerous, and provision of both aerobic and anaerobic energy contributes energy for athletic success. Together, the aerobic energy production using fat and carbohydrate as fuels and the anaerobic energy provision from PCr breakdown and carbohydrate use in the glycolytic pathway permit Olympic athletes to meet the high energy needs of particular events or sports.

The various metabolic pathways are regulated by a range of intramuscular and hormonal signals that influence enzyme activation and substrate availability, thus ensuring that the rate of ATP resynthesis is closely matched to the ATP demands of exercise. Regular training and various nutritional interventions have been used to enhance fatigue resistance via modulation of substrate availability and the effects of metabolic end products.

The understanding of exercise energy provision, the regulation of metabolism and the use of fat and carbohydrate fuels during exercise has increased over more than 100 years, on the basis of studies using various methods including indirect calorimetry, tissue samples from contracting skeletal muscle, metabolic-tracer sampling, isolated skeletal muscle preparations, and analysis of whole-body and regional arteriovenous blood samples. However, in virtually all areas of the regulation of fat and carbohydrate metabolism, much remains unknown. The introduction of molecular biology techniques has provided opportunities for further insights into the acute and chronic responses to exercise and their regulation, but even those studies are limited by the ability to repeatedly sample muscle in human participants to fully examine the varied time courses of key events. The ability to fully translate findings from in vitro experiments and animal studies to exercising humans in competitive settings remains limited.

The field also continues to struggle with measures specific to the various compartments that exist in the cell, and knowledge remains lacking regarding the physical structures and scaffolding inside these compartments, and the communication between proteins and metabolic pathways within compartments. A clear example of these issues is in studying the events that occur in the mitochondria during exercise. One area that has not advanced as rapidly as needed is the ability to non-invasively measure the fuels, metabolites and proteins in the various important muscle cell compartments that are involved in regulating metabolism during exercise. Although magnetic resonance spectroscopy has been able to measure certain compounds non-invasively, measuring changes that occur with exercise at the molecular and cellular levels is generally not possible.

Some researchers are investigating exercise metabolism at the whole-body level through a physiological approach, and others are examining the intricacies of cell signalling and molecular changes through a reductionist approach. New opportunities exist for the integrated use of genomics, proteomics, metabolomics and systems biology approaches in data analyses, which should provide new insights into the molecular regulation of exercise metabolism. Many 
questions remain in every area of energy metabolism, the regulation of fat and carbohydrate metabolism during exercise, optimal training interventions and the potential for manipulation of metabolic responses for ergogenic benefits. Exercise biology will thus continue to be a fruitful research area for many years as researchers seek a greater understanding of the metabolic bases for the athletic successes that will be enjoyed and celebrated during the quadrennial Olympic festival of sport.

Received: 20 April 2020; Accepted: 25 June 2020;

Published online: 3 August 2020

\section{References}

1. Hawley, J. A., Hargreaves, M., Joyner, M. J. \& Zierath, J. R. Integrative biology of exercise. Cell 159, 738-749 (2014).

2. Sahlin, K., Tonkonogi, M. \& Söderlund, K. Energy supply and muscle fatigue in humans. Acta Physiol. Scand. 162, 261-266 (1998).

3. Medbø, J. I. \& Tabata, I. Anaerobic energy release in working muscle during $30 \mathrm{~s}$ to $3 \mathrm{~min}$ of exhausting bicycling. J. Appl. Physiol. 75, 1654-1660 (1993).

4. Parolin, M. L. et al. Regulation of skeletal muscle glycogen phosphorylase and PDH during maximal intermittent exercise. Am. J. Physiol. 277, E890-E900 (1999).

5. Greenhaff, P. L. et al. The metabolic responses of human type I and II muscle fibres during maximal treadmill sprinting. J. Physiol. (Lond.) 478, 149-155 (1994).

6. Medbø, J. I. \& Tabata, I. Relative importance of aerobic and anaerobic energy release during short-lasting exhausting bicycle exercise. J. Appl. Physiol. 67, 1881-1886 (1989).

7. Tesch, P. A., Colliander, E. B. \& Kaiser, P. Muscle metabolism during intense, heavy-resistance exercise. Eur. J. Appl. Physiol. Occup. Physiol. 55, 362-366 (1986).

8. Koopman, R. et al. Intramyocellular lipid and glycogen content are reduced following resistance exercise in untrained healthy males. Eur. J. Appl. Physiol. 96, 525-534 (2006).

9. Hawley, J. A. \& Leckey, J. J. Carbohydrate dependence during prolonged, intense endurance exercise. Sports Med. 45 (Suppl. 1), S5-S12 (2015).

10. O’Brien, M. J., Viguie, C. A., Mazzeo, R. S. \& Brooks, G. A. Carbohydrate dependence during marathon running. Med. Sci. Sports Exerc. 25, 1009-1017 (1993).

11. Romijn, J. A. et al. Regulation of endogenous fat and carbohydrate metabolism in relation to exercise intensity and duration. Am. J. Physiol. 265, E380-E391 (1993).

12. van Loon, L. J., Greenhaff, P. L., Constantin-Teodosiu, D., Saris, W. H. \& Wagenmakers, A. J. The effects of increasing exercise intensity on muscle fuel utilisation in humans. J. Physiol. (Lond.) 536, 295-304 (2001).

13. Bergström, J. \& Hultman, E. A study of the glycogen metabolism during exercise in man. Scand. J. Clin. Lab. Invest. 19, 218-228 (1967).

14. Wahren, J., Felig, P., Ahlborg, G. \& Jorfeldt, L. Glucose metabolism during leg exercise in man. J. Clin. Invest. 50, 2715-2725 (1971).

15. Ahlborg, G., Felig, P., Hagenfeldt, L., Hendler, R. \& Wahren, J. Substrate turnover during prolonged exercise in man. J. Clin. Invest. 53, 1080-1090 (1974).

16. Watt, M. J., Heigenhauser, G. J. F., Dyck, D. J. \& Spriet, L. L. Intramuscular triacylglycerol, glycogen and acetyl group metabolism during $4 \mathrm{~h}$ of moderate exercise in man. J. Physiol. (Lond.) 541, 969-978 (2002).

17. van Loon, L. J. et al. Inhibition of adipose tissue lipolysis increases intramuscular lipid and glycogen use in vivo in humans. Am. J. Physiol. Endocrinol. Metab. 289, E482-E493 (2005)

18. Wasserman, D. H. Four grams of glucose. Am. J. Physiol. Endocrinol. Metab. 296, E11-E21 (2009).

19. Coggan, A. R., Swanson, S. C., Mendenhall, L. A., Habash, D. L. \& Kien, C. L. Effect of endurance training on hepatic glycogenolysis and gluconeogenesis during prolonged exercise in men. Am. J. Physiol. 268, E375-E383 (1995)

20. Coyle, E. F. et al. Carbohydrate feeding during prolonged strenuous exercise can delay fatigue. J. Appl. Physiol. 55, 230-235 (1983).

21. Horowitz, J. F. \& Klein, S. Lipid metabolism during endurance exercise. Am. J. Clin. Nutr. 72 (Suppl. 2), 558S-563S (2000).

22. Kiens, B. Skeletal muscle lipid metabolism in exercise and insulin resistance. Physiol. Rev. 86, 205-243 (2006).

23. Stellingwerff, T. et al. Significant intramyocellular lipid use during prolonged cycling in endurance-trained males as assessed by three different methodologies. Am. J. Physiol. Endocrinol. Metab. 292, E1715-E1723 (2007).

24. Spriet, L. L., Howlett, R. A. \& Heigenhauser, G. J. F. An enzymatic approach to lactate production in human skeletal muscle during exercise. Med. Sci. Sports Exerc. 32, 756-763 (2000)
25. Brooks, G. A. The lactate shuttle during exercise and recovery. Med. Sci. Sports Exerc. 18, 360-368 (1986).

26. Miller, B. F. et al. Lactate and glucose interactions during rest and exercise in men: effect of exogenous lactate infusion. J. Physiol. (Lond.) $\mathbf{5 4 4}$ 963-975 (2002).

27. Medbø, J. I., Jebens, E., Noddeland, H., Hanem, S. \& Toska, K. Lactate elimination and glycogen resynthesis after intense bicycling. Scand. J. Clin. Lab. Invest. 66, 211-226 (2006).

28. Hashimoto, T., Hussien, R., Oommen, S., Gohil, K. \& Brooks, G. A. Lactate sensitive transcription factor network in L6 cells: activation of MCT1 and mitochondrial biogenesis. FASEB J. 21, 2602-2612 (2007).

29. Takahashi, H. et al. TGF- $\beta 2$ is an exercise-induced adipokine that regulates glucose and fatty acid metabolism. Nat. Metab 1, 291-303 (2019).

30. Scheiman, J. et al. Meta-omics analysis of elite athletes identifies a performance-enhancing microbe that functions via lactate metabolism. Nat. Med. 25, 1104-1109 (2019).

31. Rennie, M. J. et al. Effect of exercise on protein turnover in man. Clin. Sci. (Lond.) 61, 627-639 (1981).

32. Wagenmakers, A. J. M. et al. Carbohydrate supplementation, glycogen depletion, and amino acid metabolism during exercise. Am. J. Physiol. 260, E883-E890 (1991)

33. Howarth, K. R. et al. Effect of glycogen availability on human skeletal muscle protein turnover during exercise and recovery. J. Appl. Physiol. 109, 431-438 (2010).

34. McKenzie, S. et al. Endurance exercise training attenuates leucine oxidation and BCOAD activation during exercise in humans. Am. J. Physiol. Endocrinol. Metab. 278, E580-E587 (2000).

35. Wilkinson, S. B. et al. Differential effects of resistance and endurance exercise in the fed state on signalling molecule phosphorylation and protein synthesis in human muscle. J. Physiol. (Lond.) 586, 3701-3717 (2008).

36. Egan, B. \& Zierath, J. R. Exercise metabolism and the molecular regulation of skeletal muscle adaptation. Cell Metab. 17, 162-184 (2013).

37. Spriet, L. L. New insights into the interaction of carbohydrate and fat metabolism during exercise. Sports Med. 44 (Suppl. 1), S87-S96 (2014).

38. Hargreaves, M. \& Spriet, L. L. Exercise metabolism: fuels for the fire. Cold Spring Harb. Perspect. Med. 8, a029744 (2018).

39. Richter, E. A., Ruderman, N. B., Gavras, H., Belur, E. R. \& Galbo, H. Muscle glycogenolysis during exercise: dual control by epinephrine and contractions. Am. J. Physiol. 242, E25-E32 (1982).

40. Gaitanos, G. C., Williams, C., Boobis, L. H. \& Brooks, S. Human muscle metabolism during intermittent maximal exercise. J. Appl. Physiol. 75, 712-719 (1993).

41. Kowalchuk, J. M., Heigenhauser, G. J., Lindinger, M. I., Sutton, J. R. \& Jones, N. L. Factors influencing hydrogen ion concentration in muscle after intense exercise. J. Appl. Physiol. 65, 2080-2089 (1988).

42. Howlett, R. A. et al. Regulation of skeletal muscle glycogen phosphorylase and PDH at varying exercise power outputs. Am. J. Physiol. 275, R418-R425 (1998).

43. Wojtaszewski, J. F., Nielsen, P., Hansen, B. F., Richter, E. A. \& Kiens, B. Isoform-specific and exercise intensity-dependent activation of 5 -AMP-activated protein kinase in human skeletal muscle. J. Physiol. (Lond.) 528, 221-226 (2000).

44. Chen, Z.-P. et al. AMPK signaling in contracting human skeletal muscle: acetyl-CoA carboxylase and NO synthase phosphorylation. Am. J. Physiol. Endocrinol. Metab. 279, E1202-E1206 (2000).

45. Stephens, T. J. et al. Progressive increase in human skeletal muscle AMPK $\alpha 2$ activity and ACC phosphorylation during exercise. Am. J. Physiol. Endocrinol. Metab. 282, E688-E694 (2002).

46. Yu, M. et al. Metabolic and mitogenic signal transduction in human skeletal muscle after intense cycling exercise. J. Physiol. (Lond.) 546, 327-335 (2003).

47. Rose, A. J. \& Hargreaves, M. Exercise increases $\mathrm{Ca}^{2+}$-calmodulin-dependent protein kinase II activity in human skeletal muscle. J. Physiol. (Lond.) 553, 303-309 (2003).

48. McConell, G. K. It's well and truly time to stop stating that AMPK regulates glucose uptake and fat oxidation during exercise. Am. J. Physiol. Endocrinol. Metab. 318, E564-E567 (2020).

49. Hoffman, N. J. et al. Global phosphoproteomic analysis of human skeletal muscle reveals a network of exercise-regulated kinases and AMPK substrates. Cell Metab. 22, 922-935 (2015).

50. Nelson, M. E. et al. Phosphoproteomics reveals conserved exercise-stimulated signaling and AMPK regulation of store-operated calcium entry. EMBO J. 38, e102578 (2019).

51. Needham, E. J. et al. Phosphoproteomics of acute cell stressors targeting exercise signaling networks reveal drug interactions regulating protein secretion. Cell Rep. 29, 1524-1538.e6 (2019).

52. Perry, C. G. R. et al. Mitochondrial creatine kinase activity and phosphate shuttling are acutely regulated by exercise in human skeletal muscle. J. Physiol. (Lond.) 590, 5475-5486 (2012). 
53. Miotto, P. M. \& Holloway, G. P. In the absence of phosphate shuttling, exercise reveals the in vivo importance of creatine-independent mitochondrial ADP transport. Biochem. J. 473, 2831-2843 (2016).

54. Holloway, G. P. Nutrition and training influences on the regulation of mitochondrial adenosine diphosphate sensitivity and bioenergetics. Sports Med. 47, 13-21 (2017). Suppl 1.

55. Watt, M. J., Heigenhauser, G. J. F. \& Spriet, L. L. Effects of dynamic exercise intensity on the activation of hormone-sensitive lipase in human skeletal muscle. J. Physiol. (Lond.) 547, 301-308 (2003).

56. Talanian, J. L. et al. Beta-adrenergic regulation of human skeletal muscle hormone sensitive lipase activity during exercise onset. Am. J. Physiol. 291, R1094-R1099 (2006)

57. Richter, E. A. \& Hargreaves, M. Exercise, GLUT4, and skeletal muscle glucose uptake. Physiol. Rev. 93, 993-1017 (2013).

58. Sylow, L., Kleinert, M., Richter, E. A. \& Jensen, T. E. Exercise-stimulated glucose uptake: regulation and implications for glycaemic control. Nat. Rev. Endocrinol. 13, 133-148 (2017).

59. Holloway, G. P. et al. Mitochondrial long chain fatty acid oxidation, fatty acid translocase/CD36 content and carnitine palmitoyltransferase I activity in human skeletal muscle during aerobic exercise. J. Physiol. (Lond.) 571, 201-210 (2006).

60. Bradley, N. S. et al. Acute endurance exercise increases plasma membrane fatty acid transport proteins in rat and human skeletal muscle. Am. J. Physiol. Endocrinol. Metab. 302, E183-E189 (2012).

61. Smith, B. K. et al. FAT/CD36 is located on the outer mitochondrial membrane, upstream of long-chain acyl-CoA synthetase, and regulates palmitate oxidation. Biochem. J. 437, 125-134 (2011).

62. Smith, B. K., Bonen, A. \& Holloway, G. P. A dual mechanism of action for skeletal muscle FAT/CD36 during exercise. Exerc. Sport Sci. Rev. 40, 211-217 (2012).

63. Petrick, H. L. \& Holloway, G. P. High intensity exercise inhibits carnitine palmitoyltransferase-I sensitivity to L-carnitine. Biochem. J. 476 547-558 (2019).

64. Krustrup, P. et al. Muscle and blood metabolites during a soccer game: implications for sprint performance. Med. Sci. Sports Exerc. 38, 1165-1174 (2006).

65. Achten, J. \& Jeukendrup, A. E. Maximal fat oxidation during exercise in trained men. Int. J. Sports Med. 24, 603-608 (2003).

66. Harris, R. C. et al. The time course of phosphorylcreatine resynthesis during recovery of the quadriceps muscle in man. Pflugers Arch. 367, 137-142 (1976).

67. Taylor, J. L., Amann, M., Duchateau, J., Meeusen, R. \& Rice, C. L. Neural contributions to muscle fatigue: from the brain to the muscle and back again. Med. Sci. Sports Exerc. 48, 2294-2306 (2016)

68. Allen, D. G., Lamb, G. D. \& Westerblad, H. Skeletal muscle fatigue: cellular mechanisms. Physiol. Rev. 88, 287-332 (2008).

69. Amann, M. Central and peripheral fatigue: interaction during cycling exercise in humans. Med. Sci. Sports Exerc. 43, 2039-2045 (2011).

70. Burke, L. M. \& Hawley, J. A. Swifter, higher, stronger: what's on the menu? Science 362, 781-787 (2018).

71. Hawley, J. A., Burke, L. M., Phillips, S. M. \& Spriet, L. L. Nutritiona modulation of training-induced skeletal muscle adaptations. J. Appl. Physiol. 110, 834-845 (2011).

72. Maughan, R. J. et al. IOC consensus statement: dietary supplements and the high-performance athlete. Br. J. Sports Med. 52, 439-455 (2018).

73. Roberts, A. D., Billeter, R. \& Howald, H. Anaerobic muscle enzyme changes after interval training. Int. J. Sports Med. 3, 18-21 (1982).

74. Sharp, R. L., Costill, D. L., Fink, W. J. \& King, D. S. Effects of eight weeks of bicycle ergometer sprint training on human muscle buffer capacity. Int. J. Sports Med. 7, 13-17 (1986).

75. Weston, A. R. et al. Skeletal muscle buffering capacity and endurance performance after high-intensity interval training by well-trained cyclists. Eur. J. Appl. Physiol. Occup. Physiol. 75, 7-13 (1997).

76. McKenna, M. J., Heigenhauser, G. J. F., McKelvie, R. S., MacDougall, J. D. \& Jones, N. L. Sprint training enhances ionic regulation during intense exercise in men. J. Physiol. (Lond.) 501, 687-702 (1997).

77. Gibala, M. J., Little, J. P., Macdonald, M. J. \& Hawley, J. A. Physiological adaptations to low-volume, high-intensity interval training in health and disease. J. Physiol. (Lond.) 590, 1077-1084 (2012).

78. Lundby, C., Montero, D. \& Joyner, M. Biology of $\mathrm{VO}_{2}$ max: looking under the physiology lamp. Acta Physiol. (Oxf.) 220, 218-228 (2017).

79. Amann, M. \& Calbet, J. A. Convective oxygen transport and fatigue. J. Appl. Physiol. 104, 861-870 (2008).

80. Holloszy, J. O. \& Coyle, E. F. Adaptations of skeletal muscle to endurance exercise and their metabolic consequences. J. Appl. Physiol. 56, 831-838 (1984).

81. Chesley, A., Heigenhauser, G. J. \& Spriet, L. L. Regulation of muscle glycogen phosphorylase activity following short-term endurance training. Am. J. Physiol. 270, E328-E335 (1996).
82. Leblanc, P. J., Howarth, K. R., Gibala, M. J. \& Heigenhauser, G. J. Effects of 7 wk of endurance training on human skeletal muscle metabolism during submaximal exercise. J. Appl. Physiol. 97, 2148-2153 (2004).

83. Coyle, E. F., Coggan, A. R., Hopper, M. K. \& Walters, T. J. Determinants of endurance in well-trained cyclists. J. Appl. Physiol. 64, 2622-2630 (1988).

84. Westgarth-Taylor, C. et al. Metabolic and performance adaptations to interval training in endurance-trained cyclists. Eur. J. Appl. Physiol. Occup. Physiol. 75, 298-304 (1997).

85. Seynnes, O. R., de Boer, M. \& Narici, M. V. Early skeletal muscle hypertrophy and architectural changes in response to high-intensity resistance training. J. Appl. Physiol. 102, 368-373 (2007).

86. Harris, R. C., Söderlund, K. \& Hultman, E. Elevation of creatine in resting and exercised muscle of normal subjects by creatine supplementation. Clin. Sci. (Lond.) 83, 367-374 (1992).

87. Hultman, E., Söderlund, K., Timmons, J. A., Cederblad, G. \& Greenhaff, P. L. Muscle creatine loading in men. J. Appl. Physiol. 81, 232-237 (1996).

88. Greenhaff, P. L. et al. Influence of oral creatine supplementation of muscle torque during repeated bouts of maximal voluntary exercise in man. Clin. Sci. (Lond.) 84, 565-571 (1993).

89. Casey, A., Constantin-Teodosiu, D., Howell, S., Hultman, E. \& Greenhaff, P. L. Creatine ingestion favorably affects performance and muscle metabolism during maximal exercise in humans. Am. J. Physiol. 271, E31-E37 (1996).

90. Vandenberghe, $\mathrm{K}$. et al. Long-term creatine intake is beneficial to muscle performance during resistance training. J. Appl. Physiol. 83, 2055-2063 (1997)

91. Hermansen, L., Hultman, E. \& Saltin, B. Muscle glycogen during prolonged severe exercise. Acta Physiol. Scand. 71, 129-139 (1967).

92. Ørtenblad, N., Westerblad, H. \& Nielsen, J. Muscle glycogen stores and fatigue. J. Physiol. 591, 4405-4413 (2013).

93. Matsui, T. et al. Brain glycogen decreases during prolonged exercise. J. Physiol. (Lond.) 589, 3383-3393 (2011).

94. Bergström, J., Hermansen, L., Hultman, E. \& Saltin, B. Diet, muscle glycogen and physical performance. Acta Physiol. Scand. 71, 140-150 (1967).

95. Hawley, J. A., Schabort, E. J., Noakes, T. D. \& Dennis, S. C. Carbohydrateloading and exercise performance: an update. Sports Med. 24, 73-81 (1997).

96. Balsom, P. D., Gaitanos, G. C., Söderlund, K. \& Ekblom, B. High-intensity exercise and muscle glycogen availability in humans. Acta Physiol. Scand. 165, 337-345 (1999).

97. Coyle, E. F., Coggan, A. R., Hemmert, M. K. \& Ivy, J. L. Muscle glycogen utilization during prolonged strenuous exercise when fed carbohydrate. J. Appl. Physiol. 61, 165-172 (1986).

98. Coggan, A. R. \& Coyle, E. F. Reversal of fatigue during prolonged exercise by carbohydrate infusion or ingestion. J. Appl. Physiol. 63, 2388-2395 (1987).

99. Hargreaves, M. \& Briggs, C. A. Effect of carbohydrate ingestion on exercise metabolism. J. Appl. Physiol. 65, 1553-1555 (1988).

100. Jeukendrup, A. E. et al. Carbohydrate ingestion can completely suppress endogenous glucose production during exercise. Am. J. Physiol. 276, E672-E683 (1999).

101. McConell, G., Fabris, S., Proietto, J. \& Hargreaves, M. Effect of carbohydrate ingestion on glucose kinetics during exercise. J. Appl. Physiol. 77, 1537-1541 (1994)

102. Nybo, L. CNS fatigue and prolonged exercise: effect of glucose supplementation. Med. Sci. Sports Exerc. 35, 589-594 (2003).

103. Snow, R. J., Carey, M. F., Stathis, C. G., Febbraio, M. A. \& Hargreaves, M. Effect of carbohydrate ingestion on ammonia metabolism during exercise in humans. J. Appl. Physiol. 88, 1576-1580 (2000)

104. Chambers, E. S., Bridge, M. W. \& Jones, D. A. Carbohydrate sensing in the human mouth: effects on exercise performance and brain activity. J. Physiol. (Lond.) 587, 1779-1794 (2009).

105. Costill, D. L. et al. Effects of elevated plasma FFA and insulin on muscle glycogen usage during exercise. J. Appl. Physiol. 43, 695-699 (1977)

106. Vukovich, M. D. et al. Effect of fat emulsion infusion and fat feeding on muscle glycogen utilization during cycle exercise. J. Appl. Physiol. $\mathbf{7 5}$, 1513-1518 (1993).

107. Odland, L. M., Heigenhauser, G. J., Wong, D., Hollidge-Horvat, M. G. \& Spriet, L. L. Effects of increased fat availability on fat-carbohydrate interaction during prolonged exercise in men. Am. J. Physiol. 274, R894-R902 (1998).

108. Phinney, S. D., Bistrian, B. R., Evans, W. J., Gervino, E. \& Blackburn, G. L. The human metabolic response to chronic ketosis without caloric restriction: preservation of submaximal exercise capability with reduced carbohydrate oxidation. Metabolism 32, 769-776 (1983).

109. Burke, L. M. et al. Effect of fat adaptation and carbohydrate restoration on metabolism and performance during prolonged cycling. J. Appl. Physiol. 89, 2413-2421 (2000)

110. Havemann, L. et al. Fat adaptation followed by carbohydrate loading compromises high-intensity sprint performance. J. Appl. Physiol. 100 194-202 (2006)

111. Stellingwerff, T. et al. Decreased PDH activation and glycogenolysis during exercise following fat adaptation with carbohydrate restoration. Am. J. Physiol. Endocrinol. Metab. 290, E380-E388 (2006) 
112. Burke, L. M. et al. Low carbohydrate, high fat diet impairs exercise economy and negates the performance benefit from intensified training in elite race walkers. J. Physiol. (Lond.) 595, 2785-2807 (2017).

113. Paoli, A., Bianco, A. \& Grimaldi, K. A. The ketogenic diet and sport: a possible marriage. Exerc. Sport Sci. Rev. 43, 153-162 (2015).

114. Kiens, B. \& Astrup, A. Ketogenic diets for fat loss and exercise performance: benefits and safety? Exerc. Sport Sci. Rev. 43, 109 (2015).

115. Helge, J. W., Richter, E. A. \& Kiens, B. Interaction of training and diet on metabolism and endurance during exercise in man. J. Physiol. (Lond.) 492, 293-306 (1996).

116. Yeo, W. K. et al. Skeletal muscle adaptation and performance responses to once a day versus twice every second day endurance training regimens. J. Appl. Physiol. 105, 1462-1470 (2008).

117. Hulston, C. J. et al. Training with low muscle glycogen enhances fat metabolism in well-trained cyclists. Med. Sci. Sports Exerc. 42, 2046-2055 (2010).

118. Kirwan, J. P. et al. Carbohydrate balance in competitive runners during successive days of intense training. J. Appl. Physiol. 65, 2601-2606 (1988).

119. Cox, P. J. et al. Nutritional ketosis alters fuel preference and thereby endurance performance in athletes. Cell Metab. 24, 256-268 (2016).

120. Shaw, D. M., Merien, F., Braakhuis, A., Maunder, E. \& Dulson, D. K. Exogenous ketone supplementation and keto-adaptation for endurance performance: disentangling the effects of two distinct metabolic states. Sports Med. 50, 641-656 (2020).

121. Evans, M., McSwiney, F. T., Brady, A. J. \& Egan, B. No benefit of ingestion of a ketone monoester supplement on $10-\mathrm{km}$ running performance. Med. Sci. Sports Exerc. 51, 2506-2515 (2019).

122. Prins, P. J. et al. Effects of an exogenous ketone supplement on five-kilometer running performance. J. Hum. Kinet. 72, 115-127 (2020).

123. Dearlove, D. J., Faull, O. K., Rolls, E., Clarke, K. \& Cox, P. J. Nutritional ketoacidosis during incremental exercise in healthy athletes. Front. Physiol. 10, 290 (2019).

124. Leckey, J. J., Ross, M. L., Quod, M., Hawley, J. A. \& Burke, L. M. Ketone diester ingestion impairs time-trial performance in professional cyclists. Front. Physiol. 8, 806 (2017).

125. Costill, D. L., Dalsky, G. P. \& Fink, W. J. Effects of caffeine ingestion on metabolism and exercise performance. Med. Sci. Sports 10, 155-158 (1978).

126. Graham, T. E. \& Spriet, L. L. Performance and metabolic responses to a high caffeine dose during prolonged exercise. J. Appl. Physiol. 71, 2292-2298 (1991).

127. Spriet, L. L. et al. Caffeine ingestion and muscle metabolism during prolonged exercise in humans. Am. J. Physiol. 262, E891-E898 (1992).

128. Graham, T. E., Helge, J. W., MacLean, D. A., Kiens, B. \& Richter, E. A. Caffeine ingestion does not alter carbohydrate or fat metabolism in human skeletal muscle during exercise. J. Physiol. (Lond.) 529, 837-847 (2000).

129. Graham, T. E. \& Spriet, L. L. Metabolic, catecholamine, and exercise performance responses to various doses of caffeine. J. Appl. Physiol. 78, 867-874 (1995).

130. Desbrow, B. et al. The effects of different doses of caffeine on endurance cycling time trial performance. J. Sports Sci. 30, 115-120 (2012).

131. Cole, K. J. et al. Effect of caffeine ingestion on perception of effort and subsequent work production. Int. J. Sport Nutr. 6, 14-23 (1996).

132. Kalmar, J. M. \& Cafarelli, E. Caffeine: a valuable tool to study central fatigue in humans? Exerc. Sport Sci. Rev. 32, 143-147 (2004).

133. Spriet, L. L. Exercise and sport performance with low doses of caffeine. Sports Med. 44, S175-S184 (2014). Suppl 2.

134. Wickham, K. A. \& Spriet, L. L. Administration of caffeine in alternate forms. Sports Med. 48, 79-91 (2018). Suppl 1.

135. Barnett, C. et al. Effect of L-carnitine supplementation on muscle and blood carnitine content and lactate accumulation during high-intensity sprint cycling. Int. J. Sport Nutr. 4, 280-288 (1994).

136. Stephens, F. B., Evans, C. E., Constantin-Teodosiu, D. \& Greenhaff, P. L. Carbohydrate ingestion augments L-carnitine retention in humans. J. Appl. Physiol. 102, 1065-1070 (2007a).

137. Wall, B. T. et al. Chronic oral ingestion of L-carnitine and carbohydrate increases muscle carnitine content and alters muscle fuel metabolism during exercise in humans. J. Physiol. (Lond.) 589, 963-973 (2011).

138. Stephens, F. B. et al. Skeletal muscle carnitine loading increases energy expenditure, modulates fuel metabolism gene networks and prevents body fat accumulation in humans. J. Physiol. (Lond.) 591, 4655-4666 (2013).

139. Stephens, F. B., Constantin-Teodosiu, D., Laithwaite, D., Simpson, E. J. \& Greenhaff, P. L. A threshold exists for the stimulatory effect of insulin on plasma L-carnitine clearance in humans. Am. J. Physiol. Endocrinol. Metab. 292, E637-E641 (2007b).

140. Larsen, F. J., Weitzberg, E., Lundberg, J. O. \& Ekblom, B. Effects of dietary nitrate on oxygen cost during exercise. Acta Physiol. (Oxf.) 191, 59-66 (2007).

141. Bailey, S. J. et al. Dietary nitrate supplementation reduces the $\mathrm{O}_{2}$ cost of low-intensity exercise and enhances tolerance to high-intensity exercise in humans. J. Appl. Physiol. 107, 1144-1155 (2009).
142. Bailey, S. J. et al. Dietary nitrate supplementation enhances muscle contractile efficiency during knee-extensor exercise in humans. J. Appl. Physiol. 109, 135-148 (2010).

143. Lansley, K. E. et al. Acute dietary nitrate supplementation improves cycling time trial performance. Med. Sci. Sports Exerc. 43, 1125-1131 (2011).

144. Boorsma, R. K., Whitfield, J. \& Spriet, L. L. Beetroot juice supplementation does not improve performance of elite 1500-m runners. Med. Sci. Sports Exerc. 46, 2326-2334 (2014).

145. Nyakayiru, J. M. et al. No effect of acute and 6-day nitrate supplementation on $\mathrm{VO}_{2}$ and time-trial performance in highly trained cyclists. Int. J. Sport Nutr. Exerc. Metab. 27, 11-17 (2017).

146. Jones, A. M., Thompson, C., Wylie, L. J. \& Vanhatalo, A. Dietary nitrate and physical performance. Annu. Rev. Nutr. 38, 303-328 (2018).

147. Whitfield, J. et al. Beetroot juice increases human muscle force without changing $\mathrm{Ca}^{2+}$-handling proteins. Med. Sci. Sports Exerc. 49, 2016-2024 (2017)

148. Coggan, A. R. \& Peterson, L. R. Dietary nitrate enhances the contractile properties of human skeletal muscle. Exerc. Sport Sci. Rev. 46, 254-261 (2018).

149. Whitfield, J. et al. Beetroot juice supplementation reduces whole body oxygen consumption but does not improve indices of mitochondrial efficiency in human skeletal muscle. J. Physiol. (Lond.) 594, 421-435 (2016).

150. Larsen, F. J. et al. Dietary inorganic nitrate improves mitochondrial efficiency in humans. Cell Metab. 13, 149-159 (2011).

151. Ntessalen, M. et al. Inorganic nitrate and nitrite supplementation fails to improve skeletal muscle mitochondrial efficiency in mice and humans. Am. J. Clin. Nutr. 111, 79-89 (2020)

152. Sahlin, K. \& Ren, J.-M. Relationship of contraction capacity to metabolic changes during recovery from a fatiguing contraction. J. Appl. Physiol. 67, 648-654 (1989).

153. Sutton, J. R., Jones, N. L. \& Toews, C. J. Effect of $\mathrm{pH}$ on muscle glycolysis during exercise. Clin. Sci. (Lond.) 61, 331-338 (1981).

154. Wilkes, D., Gledhill, N. \& Smyth, R. Effect of acute induced metabolic alkalosis on 800-m racing time. Med. Sci. Sports Exerc. 15, 277-280 (1983).

155. Costill, D. L., Verstappen, F., Kuipers, H., Janssen, E. \& Fink, W. Acid-base balance during repeated bouts of exercise: influence of $\mathrm{HCO}_{3}$. Int. J. Sports Med. 5, 228-231 (1984).

156. Hollidge-Horvat, M. G., Parolin, M. L., Wong, D., Jones, N. L. \& Heigenhauser, G. J. Effect of induced metabolic alkalosis on human skeletal muscle metabolism during exercise. Am. J. Physiol. Endocrinol. Metab. 278, E316-E329 (2000).

157. Street, D., Nielsen, J. J., Bangsbo, J. \& Juel, C. Metabolic alkalosis reduces exercise-induced acidosis and potassium accumulation in human skeletal muscle interstitium. J. Physiol. (Lond.) 566, 481-489 (2005).

158. Sostaric, S. M. et al. Alkalosis increases muscle $\mathrm{K}^{+}$release, but lowers plasma $\left[\mathrm{K}^{+}\right]$and delays fatigue during dynamic forearm exercise. J. Physiol. (Lond.) 570, 185-205 (2006)

159. Parkhouse, W. S., McKenzie, D. C., Hochachka, P. W. \& Ovalle, W. K. Buffering capacity of deproteinized human vastus lateralis muscle. J. Appl. Physiol. 58, 14-17 (1985).

160. Derave, $W$. et al. $\beta$-Alanine supplementation augments muscle carnosine content and attenuates fatigue during repeated isokinetic contraction bouts in trained sprinters. J. Appl. Physiol. 103, 1736-1743 (2007).

161. Hill, C. A. et al. Influence of $\beta$-alanine supplementation on skeletal muscle carnosine concentrations and high intensity cycling capacity. Amino Acids 32, 225-233 (2007).

162. Powers, S. K. \& Jackson, M. J. Exercise-induced oxidative stress: cellular mechanisms and impact on muscle force production. Physiol. Rev. 88, 1243-1276 (2008).

163. Merry, T. L. \& Ristow, M. Do antioxidant supplements interfere with skeletal muscle adaptation to exercise training? J. Physiol. (Lond.) 594, 5135-5147 (2016).

164. McKenna, M. J. et al. N-acetylcysteine attenuates the decline in muscle $\mathrm{Na}^{+}, \mathrm{K}^{+}$-pump activity and delays fatigue during prolonged exercise in humans. J. Physiol. (Lond.) 576, 279-288 (2006).

165. Petersen, A. C. et al. Infusion with the antioxidant $\mathrm{N}$-acetylcysteine attenuates early adaptive responses to exercise in human skeletal muscle. Acta Physiol. (Oxf.) 204, 382-392 (2012).

166. Ristow, M. et al. Antioxidants prevent health-promoting effects of physical exercise in humans. Proc. Natl Acad. Sci. USA 106, 8665-8670 (2009).

167. Nybo, L. Hyperthermia and fatigue. J. Appl. Physiol. 104, 871-878 (2008)

168. González-Alonso, J., Mora-Rodríguez, R., Below, P. R. \& Coyle, E. F. Dehydration markedly impairs cardiovascular function in hyperthermic endurance athletes during exercise. J. Appl. Physiol. 82, 1229-1236 (1997).

169. González-Alonso, J., Calbet, J. A. \& Nielsen, B. Metabolic and thermodynamic responses to dehydration-induced reductions in muscle blood flow in exercising humans. J. Physiol. (Lond.) 520, 577-589 (1999a) 
170. Fink, W. J., Costill, D. L. \& Van Handel, P. J. Leg muscle metabolism during exercise in the heat and cold. Eur. J. Appl. Physiol. Occup. Physiol. 34, 183-190 (1975).

171. Febbraio, M. A. et al. Muscle metabolism during exercise and heat stress in trained men: effect of acclimation. J. Appl. Physiol. 76, 589-597 (1994).

172. Febbraio, M. A., Snow, R. J., Stathis, C. G., Hargreaves, M. \& Carey, M. F. Blunting the rise in body temperature reduces muscle glycogenolysis during exercise in humans. Exp. Physiol. 81, 685-693 (1996).

173. González-Alonso, J. et al. Influence of body temperature on the development of fatigue during prolonged exercise in the heat. J. Appl. Physiol. 86, 1032-1039 (1999b).

174. Hargreaves, M., Dillo, P., Angus, D. \& Febbraio, M. Effect of fluid ingestion on muscle metabolism during prolonged exercise. J. Appl. Physiol. 80, 363-366 (1996).

175. Logan-Sprenger, H. M., Heigenhauser, G. J. F., Killian, K. J. \& Spriet, L. L. Effects of dehydration during cycling on skeletal muscle metabolism in females. Med. Sci. Sports Exerc. 44, 1949-1957 (2012).

176. Costill, D. L. et al. Skeletal muscle enzymes and fiber composition in male and female track athletes. J. Appl. Physiol. 40, 149-154 (1976).

177. Costill, D. L., Fink, W. J., Getchell, L. H., Ivy, J. L. \& Witzmann, F. A. Lipid metabolism in skeletal muscle of endurance-trained males and females. J. Appl. Physiol. 47, 787-791 (1979).

178. Horton, T. J., Pagliassotti, M. J., Hobbs, K. \& Hill, J. O. Fuel metabolism in men and women during and after long-duration exercise. J. Appl. Physiol. 85, 1823-1832 (1998).

179. Friedlander, A. L. et al. Training-induced alterations of carbohydrate metabolism in women: women respond differently from men. J. Appl. Physiol. 85, 1175-1186 (1998).

180. Tarnopolsky, L. J., MacDougall, J. D., Atkinson, S. A., Tarnopolsky, M. A. \& Sutton, J. R. Gender differences in substrate for endurance exercise. J. Appl. Physiol. 68, 302-308 (1990).

181. Carter, S. L., Rennie, C. \& Tarnopolsky, M. A. Substrate utilization during endurance exercise in men and women after endurance training. Am. J. Physiol. Endocrinol. Metab. 280, E898-E907 (2001).

182. Roepstorff, C. et al. Gender differences in substrate utilization during submaximal exercise in endurance-trained subjects. Am. J. Physiol. Endocrinol. Metab. 282, E435-E447 (2002).
183. Roepstorff, C. et al. Higher skeletal muscle $\alpha 2 \mathrm{AMPK}$ activation and lower energy charge and fat oxidation in men than in women during submaximal exercise. J. Physiol. (Lond.) 574, 125-138 (2006).

184. Hamadeh, M. J., Devries, M. C. \& Tarnopolsky, M. A. Estrogen supplementation reduces whole body leucine and carbohydrate oxidation and increases lipid oxidation in men during endurance exercise. J. Clin. Endocrinol. Metab. 90, 3592-3599 (2005).

185. Hackney, A. C., McCracken-Compton, M. A. \& Ainsworth, B. Substrate responses to submaximal exercise in the midfollicular and midluteal phases of the menstrual cycle. Int. J. Sport Nutr. 4, 299-308 (1994).

186. Zderic, T. W., Coggan, A. R. \& Ruby, B. C. Glucose kinetics and substrate oxidation during exercise in the follicular and luteal phases. J. Appl. Physiol. 90, 447-453 (2001).

187. Devries, M. C., Hamadeh, M. J., Phillips, S. M. \& Tarnopolsky, M. A. Menstrual cycle phase and sex influence muscle glycogen utilization and glucose turnover during moderate-intensity endurance exercise. Am. J. Physiol. Regul. Integr. Comp. Physiol. 291, R1120-R1128 (2006).

188. Frandsen, J. et al. Menstrual cycle phase does not affect whole body peak fat oxidation rate during a graded exercise test. J. Appl. Physiol. 128, 681-687 (2020).

\section{Author contributions}

M.H. and L.L.S. conceived and prepared the original draft, revised the manuscript and prepared the figures.

\section{Competing interests}

The authors declare no competing interests.

\section{Additional information}

Correspondence should be addressed to M.H. or L.L.S.

Peer review information Primary Handling Editor: Christoph Schmitt.

Reprints and permissions information is available at www.nature.com/reprints. Publisher's note Springer Nature remains neutral with regard to jurisdictional claims in published maps and institutional affiliations.

(c) Springer Nature Limited 2020 